\title{
Exposure to chronic moderate hypoxia impacts physiological and developmental traits of European sea bass (Dicentrarchus labrax) larvae
}

\author{
Vanderplancke Gwenaëlle ${ }^{1}$, Claireaux Guy ${ }^{1,2}$, Quazuguel Patrick ${ }^{1}$, Huelvan Christine ${ }^{1}$, \\ Corporeau Charlotte ${ }^{1}$, Mazurais David ${ }^{1}$, Zambonino-Infante José-Luis ${ }^{1,{ }^{*}}$
}

${ }^{1}$ Ifremer, LEMAR UMR 6539 CNRS-UBO-IRD-Ifremer, ZI de la Pointe du Diable, CS 10070, 29280, Plouzané, France

${ }^{2}$ Université de Bretagne Occidentale, LEMAR UMR 6539 CNRS-UBO-IRD-Ifremer, ZI de la Pointe du Diable, CS 10070, 29280, Plouzané, France

* Corresponding author : José-Luis Zambonino-Infante, email address : jose.zambonino@ifremer.fr

\begin{abstract}
:
Since European sea bass (Dicentrarchus labrax) larvae occurred in coastal and estuarine waters at early life stages, they are likely to be exposed to reduced dissolved oxygen waters at a sensitive developmental stage. However, the effects of hypoxia at larval stage, which depend in part on fish species, remain very poorly documented in European sea bass. In the present study, the impacts of an experimental exposure to a chronic moderate hypoxia (40\% air saturation) between 30 and 38 days post-hatching on the physiological and developmental traits of European sea bass larvae were assessed. This study was based on the investigation of survival and growth rates, parameters related to energy metabolism [Citrate Synthase (CS) and Cytochrome-c Oxidase (COX) activities], and biological indicators of the maturation of digestive function [pancreatic (trypsin, amylase) and intestinal (Alkaline Phosphatase "AP" and Aminopeptidase-N "N-LAP") enzymes activities]. While condition of hypoxia exposure did not induce any significant mortality event, lower growth rate as well as CS/COX activity ratio was observed in the Hypoxia Treatment group. In parallel, intestinal enzyme activities were also lower under hypoxia. Altogether, the present data suggest that sea bass larvae cope with moderate hypoxia by (1) reducing processes that are costly in energy and (2) regulating mitochondria functions in order to respond to energy-demand conditions. Both these effects are associated with a delay in the maturation of the digestive function.
\end{abstract}

Keywords : Hypoxia, Fish larvae, Energy metabolism, Maturation 


\section{Abbreviations}

AP

Alkaline Phosphatase

C

Control group

cox

Cytochrome-c Oxidase

CS

Citrate Synthase

d.p.h.

Days post-hatching

$\mathrm{FI}$

Feed intake

$\mathrm{H}$

Head

HT

Hypoxia treatment

IS

Intestinal segment

N-LAP

Aminopeptidase- $\mathrm{N}$

NS

No significant differences

PS

Pancreatic segment

RMR

Routine metabolic rate

s.e.m.

Standard error of mean

$T$

Tail 
Since larvae of marine fish species hatch at an undeveloped stage, their development and ontogeny are liable to be greatly affected by biotic and abiotic conditions. This is especially true in coastal areas, which are nurseries for many marine fish species and where ecosystems are particularly impacted by human activities and global change. Among the environmental factors affecting the world's coastal waters, hypoxia is a major problem and is forecast to increase further under the combined effects of spreading coastal eutrophication and global warming (Diaz, 2001; Diaz and Rosenberg, 1995). Hypoxia episodes often coincide with periods of annual recruitment and the growth of benthic and pelagic fish species occurring in late spring and early summer (Breitburg, 1992; Pihl et al., 1991; Pihl et al., 1992). Understanding the impact of a low oxygen environment on the early life stages of fish is therefore of great importance, since fishery production relies on larval and juvenile recruitment.

Exposure of juveniles or adults from different fish species to hypoxia has been shown to notably affect fish routine metabolic rate (RMR), feed intake (FI), growth, condition factor and concentration of protein, e.g., European sea bass (Dicentrarchus labrax) (Claireaux and Lagardere, 1999; Pichavant et al., 2001; Thetmeyer et al., 1999); turbot (Scophthalmus maximus) (Pichavant et al., 2001; Pichavant et al., 2000); Amazon oscar (Astronotus crassipinis) (Almeida-Val et al., 2011); and mummichog (Fundulus heteroditus) (Rees et al., 2012). It is supposed that some of these effects can be explained by the hypoxia-induced control of fundamental processes related to energy saving. Long-term exposure to hypoxia in fish has been also shown to affect egg development and hatching success, resulting in malformation, lower fitness and high mortality rates at larval and juvenile stages, e.g., brown trout (Salmo trutta) (Massa et al., 1999; Roussel, 2007); black bream (Acanthopagrus butcheri) (Hassell et al., 2008); zebrafish (Danio rerio) (Padilla and Roth, 2001; Shang and Wu, 2004); and dogfish (Scyliorhinus canicula) (Diez and Davenport, 1990). These effects occur due to disturbances in a series of programmed, highly intricate and energy-consuming processes (Ozernyuk, 2011; Wu et al., 2006). Although it is generally accepted that early embryonic developmental stages are particularly sensitive to stresses in fish (Cameron and VonWesternhagen, 1997), post-hatching development also has windows of sensitivity to hypoxia. The effects of hypoxia exposure when applied at larval stages vary widely depending on fish species, hypoxia severity, exposure period and individual adaptive capacities (Anjos et al., 2008; Bickler and Buck, 2007). While Barrionuevo et al. (2010) 
79

80

81

82

83

84

85

86

87

88

89

90

91

92

93

94

95

96

97

98

99

100

101

102

103

104

105

106

107

108

reported that zebrafish did not respond to moderate hypoxia before 30 days post-hatching (d.p.h.), Pelster (2002) showed that exposure of the same species to 7 days of moderate hypoxia affected larval cardiac activity, cardiac output, heart rate, organ perfusion and blood vessel formation. Since hatching of marine fish species occurs at earlier stages of development compared with freshwater species, their ontogenic processes during the larval phase are likely more sensitive to hypoxic episodes. Low tolerance to hypoxia has been observed over the period of metamorphosis in sea bream (Pagrus major) (Ishibashi et al., 2005); Japanese flounder (Paralichthys olivaceu) (Ishibashi et al., 2007); and bonefish (Albula sp.) (Pfeiler, 2001). It is supposed that this sensitivity is due to the increase of metabolic rates just before and just after the flexion stage, which is a period of dramatic molecular, physiological and behavioural changes for marine fish species such as European sea bass (Mazurais et al., 2011). The European sea bass is a highly valued fish that migrates from offshore areas to the coast just after flexion stage, which occurs between 22 and 25 d.p.h. (Dufour et al., 2009; Jennings and Pawson, 1992; Pickett and Pawson, 1994). This species can therefore be exposed to hypoxic events from this stage onward. However, few studies have been published on the effects of hypoxia on larval development of this marine fish species.

The purpose of the present study was to evaluate the impact of a chronic (between 30 and 38 d.p.h., a natural hypoxia exposure window) moderate (40\% air saturation) hypoxia exposure on growth, metabolism and maturation in European sea bass larvae. To gain insight into the energy metabolism of larvae, Citrate Synthase (CS) and Cytochrome c Oxidase (COX) activities were assessed. CS and COX are key mitochondrial enzymes localized in matrix or membrane which fluctuations provide information on the properties and the numbers of the mitochondria present (Guderley, 2007; Lucassen et al., 2003). CS/COX activity ratio was used in order to estimate changing in mitochondrial size and shape in response to energydemand conditions as indicated in studies by Lucassen et al. (2003) and Ibarz et al. (2010). Finally, digestive enzyme activities [Trypsin, Amylase, Alkaline Phosphatase (AP) and Aminopeptidase-N (N-LAP)] were used as indicators of the developmental status of the fish larvae. 


\section{Larval rearing}

111 Post-hatching, larvae of European sea bass were reared under normal oxygen conditions in 8

112 tanks at $19.1 \pm 0.4{ }^{\circ} \mathrm{C}$ water temperature and $35 \pm 0.2 \%$ salinity, and were fed with Artemia

113 until 45 d.p.h according to Zambonino-Infante et al. (1996). The tanks were then divided into

114 two groups of four tanks. The Control group (or C group) was maintained under normal 115 oxygen condition (96.6 $\pm 1.3 \%$ air saturation, $7.10 \mathrm{mg} \mathrm{O}_{2} . \mathrm{L}^{-1}$ ), while larvae from the 116 challenged group, also named Hypoxia Treatment group (or HT group), were subjected to moderate hypoxia $\left(40.1 \pm 2.6 \%\right.$ air saturation, $2.95 \mathrm{mg} \mathrm{O}_{2} \cdot \mathrm{L}^{-1}$ ) for 8 days (from 30 to 38 d.p.h., Fig. 1). These hypoxia conditions had previously been determined to not induce mortality. During hypoxia exposure larvae of each group were fed with Artemia, except $24 \mathrm{~h}$ prior to samplings where larvae were left undisturbed and unfed. After the hypoxia exposure,

121 larvae continue to be fed with Artemia until the end of experimentations. It was not possible 122 to evaluate feed ingestion throughout this experiment; however, we did not notice any visible change in feeding activity in HT group during or after hypoxia exposure.

\section{Survival rate and larval growth}

125 Survival rate was estimated at 45 d.p.h. by counting the number of remaining larvae in each 126 group and taking into account the larvae collected for sampling during the experiment.

127 Growth was evaluated on four pools (1 pool from each tank) of approximately 40 larvae per sample from the beginning of hypoxia exposure (30 d.p.h.) until 45 d.p.h. (i.e. at 30, 32, 35 and 38 d.p.h - during hypoxia exposure - and at 42 and 45 d.p.h. - after the return to normoxic conditions).

\section{Larvae sampling}

132 During hypoxia exposure, five samplings (at 30, 32, 35 and 38 d.p.h. and 42 d.p.h.) were performed in order to analyse CS and COX activities. For this purpose, in each treatment group, 4 samplings ( 1 per tank) of 35 or 40 pooled larvae were for protein concentration and enzymes activities assays. Larvae were first placed on a glass maintained at $0^{\circ} \mathrm{C}$ and dissected under microscope into four parts: head "H" (just behind the eye), pancreatic segment "PS"

137 (just behind the gills) and tail "T" (point between the end of the digestive tract and the anal 138 tail) were discarded, and the intestinal segment "IS" conserved (Fig. 2). For each group, 
139 pooled IS were then weighed, placed in ice-cold lysis buffer and stored at $-80^{\circ} \mathrm{C}$ until proteins 140 extraction.

141 For digestive enzymes assays, four samplings (one per tank) of 35 larvae per group were 142 performed at 38 d.p.h. and stored at $-20^{\circ} \mathrm{C}$. Larvae were placed on an ice-chilled glass and 143 dissected under a microscope into 4 parts: head (H), pancreatic segment (PS) intestinal 144 segment (IS) and tail (T) (Fig. 2). PS and IS were then stored at $-20^{\circ} \mathrm{C}$ for later assay of their 145 respective enzymes, as previously described by Cahu and Zambonino-Infante (1994).

146 Extractions of proteins from larvae for analysis of CS and COX activities

147 Proteins were solubilized by adding 3-6 mL of ice-cold lysis buffer containing $150 \mathrm{mM} \mathrm{NaCl}$, 14810 mM Tris, 1 mM EDTA, 1 mM EGTA, 1\% Triton X-100, 0.5\% Igepal, 1 tablet of complete 149 EDTA-free protease inhibitor cocktail (Roche Pharma; Basel, Switzerland) in 25 mL buffer, $1501 \%$ phosphatase inhibitor cocktail III (Sigma-Aldrich®; St. Louis, MO, USA) and 5mM 151 NaPPi, pH 7.4. Total proteins and enzymes were then extracted as described by Le Foll et al. 152 (2007). Briefly, total proteins and enzymes lysates were obtained after homogenization with a 153 Pro Polytron ${ }^{\circledR}$ (BioBlock Scientific; Illkirch , Bas-Rhin , France) tissue disruptor. The 154 homogenates obtained were then centrifuged at $3,000 \mathrm{~g}$ for $1 \mathrm{~h}$ at $4^{\circ} \mathrm{C}$. At the end of the

155

156

157

158

159

160

161

162

163

164

165

166

167

168

169 centrifugation, the interphase containing proteins and enzymes was collected by carefully pipetting and then centrifuged at $10,000 \mathrm{~g}$ for $45 \mathrm{~min}$ at $4^{\circ} \mathrm{C}$ in order to ensure total lipid removal. The new interphase was carefully collected, aliquoted and stored at $-80^{\circ} \mathrm{C}$.

\section{Enzymatic activities assays (aerobic metabolism and larval maturation)}

CS activity was assessed in Nunc ${ }^{\mathrm{TM}}$ 96-well microplates (Thermo Scientific Inc.; Waltham, MA, USA). Data were obtained with a microplate reader (Bio-Tek ${ }^{\circledR}$ Synergy ${ }^{\mathrm{TM}}$ HT; Colmar, Haut-Rhin, France) and then treated with KC4 v3 software. The assay was adapted from Guderley et al. (2011). Briefly, CS activity was assayed for $10 \mathrm{~min}$ at wavelength $\lambda=412 \mathrm{~nm}$ and temperature $\mathrm{T}=25^{\circ} \mathrm{C}$. The microplate was prepared by mixing $20 \mu \mathrm{L}$ of sample with 160 $\mu \mathrm{L}$ of a mix consisting of $0.25 \mathrm{mM}$ Acetyl-coA, $0.125 \mathrm{mM}$ DTNB and $86.25 \mathrm{mM}$ Tris-HCl, $\mathrm{pH}=8$. The reaction was initiated by adding $20 \mu \mathrm{L} 5 \mathrm{mM}$ oxaloacetate to each well. The control used for the assay was a commercial enzyme of CS (Sigma-Aldrich® Inc.; St. Louis, MO, USA).

In parallel, COX activity was assessed using Cytochrome c Oxidase Assay Kit, CYTOCOX1 (Sigma-Aldrich ${ }^{\circledR}$ Inc.; St. Louis, MO, USA) following manufacturer’s instructions. Briefly, 
170 COX activity was assayed for 1 min at wavelength $\lambda=550 \mathrm{~nm}$ and temperature $\mathrm{T}=25^{\circ} \mathrm{C}$.

171 The reaction was prepared by mixing $350 \mu \mathrm{L}$ of assay buffer $(10 \mathrm{mM}$ Tris- $\mathrm{HCl}, 120 \mathrm{mM} \mathrm{KCl}$, $172 \mathrm{pH}=7.0), 80 \mu \mathrm{L}$ of enzyme buffer (10 mM Tris-HCl, $250 \mathrm{mM}$ sucrose, $\mathrm{pH}=7.0)$ and $20 \mu \mathrm{L}$

173 of sample. The reaction was then initiated by adding $50 \mu \mathrm{L}$ of $0.22 \mathrm{mM}$ Ferrocytochrome c 174 substrate solution.

175 Larval development was evaluated as described by Cahu and Zambonino-Infante (1995).

176 Protocols for the homogenisation of the pancreatic segments and intestine, brush border 177 purification, protein dosages and enzymatic assay procedures for Amylase, Trypsin, AP and 178 N-LAP are described in Zambonino-Infante et al. (1997). Enzyme activities were expressed as 179 specific activities, i.e., units per mg of proteins.

\section{Statistical analyses}

181 Data are presented as means \pm s.e.m. (Standard Error of Mean). Statistical analyses were 182 performed using R software (R Core Team, 2013). For all analyses, all response variables 183 were checked for normality with the Shapiro test and for equality of variances using the 184 Levene test. A regression was used in order to determine the influence of oxygen treatment on survival. A two-way ANOVAs were then used (except for survival and maturation analyses, for which a regression and a one-way ANOVA were used, respectively) to determine the influence of oxygen treatment, age of larvae (as main effects) and their interaction on each response variable. When the interaction between oxygen treatment and the age of larvae was significant, Student-test were used to determine significant differences among groups within each sampling time. An ANCOVA was used for CS/COX activity ratio analyses in order to determine the influence of oxygen treatment (as main effect) with age of larvae as co-factor. In addition, a Student-test was used to determine significant differences among groups within

193 each sampling time for CS/COX activity ratio and at 30, 38 and 45 d.p.h. for growth rate.

194 Finally, a one-way ANOVA was used in order to determine the influence of oxygen treatment 195 on larval development. Differences were considered significant at the 95\% confidence level 196 (p-value < 0.05). 
198

199

200

201

202

203

204

205

206

207

208

209

210

211

212

213

214

215

216

217

218

219

220

221

222

223

224

225

\section{Results}

No variable differed significantly between the Control (C) and the Hypoxia Treatment (HT) groups prior to the hypoxia exposure, i.e. at 30 d.p.h. just before the beginning of exposure.

\section{Survival and growth of larvae}

Survival

No significant mortality events were observed in the tanks during and after the period of exposure to hypoxia. This was confirmed by the survival rate estimated at 45 d.p.h., which was not significantly different between the two groups $(\mathrm{C}=44.9 \pm 7.2 \%$, HT $=44.7 \pm 5.3 \%$; $\mathrm{p}=1)$.

\section{Larval growth}

Growth of larvae was monitored from the beginning of hypoxia exposure (30 d.p.h.) until 45 d.p.h. (after the return to normoxic conditions). Data were transformed using cubic root following recommendations of Bureau et al. (2000) (Fig. 3). Globally, in both groups, the larval growth rate increased with the age of larvae. Statistical analyses revealed that larval growth was affected by oxygen treatment (two-way ANOVA: p < 0.001) and by the age of larvae (two-way ANOVA: p < 0.001). The interaction between oxygen treatment and the age of larvae was significant (two-way ANOVA: $\mathrm{p}<0.01$ ). While the mean larval masses were similar between the two groups at the beginning of hypoxia exposure (30 d.p.h.) ( $C=4.66 \pm$ $0.17 \mathrm{mg} ; \mathrm{HT}=4.67 \pm 0.16 \mathrm{mg}$; Student-test: $\mathrm{p}>0.5$ ), they were found significantly different at the end of hypoxia exposure (38 d.p.h.) $(\mathrm{C}=13.26 \pm 2.29 \mathrm{mg} ; \mathrm{HT}=9.23 \pm 1.73 \mathrm{mg}$; Student-test: $\mathrm{p}<0.01$ ). This data can be related to the significant impact of hypoxia exposure on the growth rate (two-way ANOVA interaction: $\mathrm{p}<0.01$ ). Furthermore, growth tend to be higher in HT group after hypoxia exposure resulting in similar mass between the two groups at 45 d.p.h. $(\mathrm{C}=31.40 \pm 2.97 \mathrm{mg}$; $\mathrm{HT}=27.79 \pm 4.18 \mathrm{mg}$; Student-test: $\mathrm{p}>0.09)$.

\section{Regulation of Citrate Synthase and Cytochrome c Oxidase activities}

CS and COX activities in the IS of larvae were assessed from the beginning of hypoxia exposure (30 d.p.h.) until 42 d.p.h. (after the return to normoxic conditions) (Fig. 4). Overall, CS and COX specific activities increased during larval development in both groups (Fig. 4 A 
226 and Fig. 4 B) (ANCOVA: p $<0.001$ and p = 0.001, respectively). During hypoxia exposure, 227 i.e. from 30 to 38 d.p.h., CS specific activity was not impacted by hypoxia exposure while 228 COX specific activity was higher in the HT group (ANCOVA: p < 0.001). Globally, the 229 CS/COX activity ratio exhibit significant fluctuations throughout the experiment (Fig. 4 C) 230 (ANCOVA: p < 0.001). During hypoxia exposure, i.e. from 30 to 38 d.p.h., CS/COX activity 231 ratio was lower in the HT group (ANCOVA: $\mathrm{p}<0.001$ ). The effect of the oxygen treatment 232 on CS/COX activity ratio is particularly marked at 32, 35 and 38 d.p.h. (Student-test: p < 233 0.001, $\mathrm{p}<0.001$ and $\mathrm{p}<0.05$, respectively). There was no more difference in CS/COX 234 activity ratio between C and HT groups 96h (42 d.p.h.) after the return to normoxic conditions 235 (Student-test: $\mathrm{p}>0.05)$.

\section{Maturation of larvae digestive functions}

237 Activities of digestive enzymes were determined in both the C and HT groups at 38 d.p.h.

238 (Table 1). For pancreatic enzymes, larvae from the HT group exhibited 25\% lower trypsin 239 specific activity and showed a significantly 150\% higher amylase specific activity than the C 240 group (one-way ANOVA: $\mathrm{p}_{\text {Trypsin }}<0.01$, $\mathrm{p}_{\text {Amylase }}<0.05$ ). For the intestinal enzymes, larvae 241 exposed to hypoxia exhibited AP and N-LAP specific activities significantly lower than those 242 from the C group by $78 \%$ and 53\%, respectively (one-way ANOVA: $\mathrm{p}_{\mathrm{AP}}=0.01$, $\mathrm{p}_{\mathrm{N}-\mathrm{LAP}}<$ $2430.01)$. 
246

247

248

249

250

251

252

253

254

255

256

257

258

259

260

261

262

263

264

265

266

267

268

269

270

271

272

273

274

275

276

277

Since they arrive on the coastline around one month after hatching (Dufour et al., 2009; Jennings and Pawson, 1992), European sea bass (Dicentrarchus labrax) are likely to experience hypoxia episodes at the end of the larval period. However, the impact of hypoxic events on their physiology at this developmental stage is still largely unknown. The present study was intended to assess the effects of moderate hypoxia (40\% air saturation) applied for a duration of 8 days on 30 day-old sea bass larvae. The hypoxia treatment did not induce any significant mortality. Moreover no significant impact on skeletal deformity rate was observed in juveniles originated from larvae of HT group (data not shown). The absence of effect on survival and malformation rates in the preset study differs from previous data showing that moderate hypoxia induces lower survival rates and higher frequency of vertebral column deformities in first feeding yellowfin tuna (Thunnus albacares) (Wexler et al., 2011) and Atlantic salmon alevins (Salmo salar) (Sanchez et al., 2011) respectively. This apparent discrepancy of response is consistent with the well admitted species-specific as well as stagespecific response of fish to hypoxia constraint (Richards et al., 2009).

We observed a lower mass in larvae from the HT group at the end of hypoxia exposure resulting from a reduction of growth during the exposition compared to the $\mathrm{C}$ group. Evaluation of food intake in larvae is not really easy and necessitates the use of ${ }^{14} \mathrm{C}$-labelled feeds (Kolkovski et al., 1997), which was not possible to perform during this experiment. However, it has been well described that hypoxia usually induces reduction in food ingestion (Lakani et al., 2013; Pichavant et al., 2001; Pichavant et al., 2000; Thetmeyer et al., 1999). Seven days after the return under normoxic conditions (i.e. at 45 d.p.h.), larvae from HT group recovered the same weight as those from the $\mathrm{C}$ group (Fig. 3) suggesting a potential compensatory growth. Yet, such a compensatory growth after hypoxia exposure was previously shown in Chinese shrimp (Fenneropenaeus chinensis) (Wei et al., 2008); it is likely that a higher number of sampling points after the return under normoxic conditions would have permitted to point out compensatory growth in our study.

In the present study, the lower trypsin specific activity in larvae originated from the HT group suggested that one week moderate hypoxia exposure impaired ingestion of fish. As mentioned by Zambonino-Infante and Cahu (2001), pancreatic maturation in sea bass larvae has been completed by 25 d.p.h. and trypsin activity can be directly related to the dietary protein intake from 35 d.p.h. Therefore, a decrease in trypsin specific activity observed after 35 d.p.h. is generally related to undernutrition (Zambonino-Infante and Cahu, 2001). Again, in the present 
study, even if we observed that larvae exposed to $40 \%$ air saturation hypoxia continued to have a certain feeding activity, we cannot exclude that they reduced their food consumption, compared to control larvae. Furthermore, in our study, the larvae which have experienced hypoxia exposure exhibited higher amylase specific activity at the same stage of development than larvae from $\mathrm{C}$ group. It is well documented that amylase specific activity decrease throughout the larval stage (Péres et al., 1996; Ribeiro et al., 1999; Zambonino-Infante and Cahu, 2001). This difference indicates that the normal decrease of amylase specific activity in larvae was delayed in the HT group. In parallel, the lower AP and N-LAP specific activities in larvae from the HT group revealed that the maturation of the enterocytes was impaired by the hypoxia episode. In marine fish species, particularly European sea bass, it is well admitted that the settlement of an efficient intestinal membrane digestion (characterised by the concomitant increase in AP and N-LAP specific activities) occurred around 30 d.p.h. at $19^{\circ} \mathrm{C}$ (Cahu and Zambonino-Infante, 1994; Zambonino-Infante and Cahu, 2001). In the present study, these developmental delays could also have contributed to a growth depression as long as the sea bass larvae were exposed to hypoxia, as already observed in fish larvae (PerezDominguez and Holt, 2006; Wexler et al., 2011).

We also found a down-regulation of CS/COX activity ratio in the HT group during hypoxia exposure. This down-regulation disappeared after the return in normoxic conditions (Fig. 4 C). This down-regulation of CS/COX activity ratio was mainly due to a significant increase in COX specific activity (Fig. 4 B) more than a decrease in CS specific activity (Fig. 4 A). The CS is a key enzyme localized in the mitochondrial matrix and is involved in the Krebs' cycle whereas COX is the terminal electron acceptor of the electron transport chain located in the mitochondrial inner membrane. These two enzymes are of great importance in aerobic metabolism and provide information on respiration metabolism capacity. The fluctuations of these two key mitochondrial enzymes provide information on the properties and the numbers of the mitochondria present (Guderley, 2007; Lucassen et al., 2003). CS/COX activity ratio could be used in order to estimate changes in mitochondrial size and shape in response to energy-demand conditions (Ibarz et al., 2010). In consequence, the decrease in CS/COX activity ratio observed in our study during the hypoxia period could reflect a lower citrate synthesis over respiratory chain capacities of mitochondria in the larvae from the HT group (Lucassen et al., 2003) as well as a modification of the size and the shape of mitochondria (Ibarz et al., 2010). The similar CS/COX activity ratio observed at 42 d.p.h. indicated that such mitochondrial changes were transient. 
311 It is interesting to note that the decrease in CS/COX activity ratio in HT group coincided with

312 a growth depression, but we were not able to establish a significant relationship between 313 growth rate and CS/COX activity ratio. Such relationship has yet been reported by Mathers et 314 al. (1992) in the saithe (Pollachius virens).

\section{Conclusion}

316 Altogether, the results obtained suggest that sea bass larvae are able to implement 317 physiological regulations in order to cope with a moderate decrease in ambient oxygen. 318 However, these regulations seemed to have a metabolic cost that impacted growth and 319 development, but not survival. Such consequences could have a strong impact on fish larvae 320 activities, especially on their capacities to escape predation, which could adversely affect the 321 recruitment of sea bass. 


\section{Funding}

324 The first author was supported by a joint Ifremer-Région Bretagne PhD grant.

\section{Author contributions}

326 Study conception and design: G. Vanderplancke, D. Mazurais, J-L. Zambonino-Infante

327 Animal experiments: G. Vanderpancke, P. Quazuguel

328 Acquisition and analysis of data: G. Vanderplancke, C. Huelvan

329 Interpretation of data: G. Vanderpancke, C. Corporeau, D. Mazurais, J-L. Zambonino-Infante

330 Drafting of manuscript: G. Vanderplancke, D. Mazurais, J-L Zambonino-Infante

331 Critical revision: D. Mazurais, J-L. Zambonino-Infante, G. Claireaux

332

333 Competing interests

334 No competing interests declared.

335

336 


\section{References List}

Almeida-Val, V. M. F., Oliveira, A. R., da Silva, M. D. P., Ferreira-Nozawa, M. S., Araujo, R. M., Val, A. L. and Nozawa, S. R. (2011). Anoxia- and hypoxia-induced expression of LDH-A* in the Amazon Oscar, Astronotus crassipinis. Genetics and Molecular Biology 34, 315-322.

Anjos, M. B., De Oliveira, R. R. and Zuanon, J. (2008). Hypoxic environments as refuge against predatory fish in the Amazonian floodplains. Brazilian Journal of Biology 68, 45-50.

Barrionuevo, W. R., Fernandes, M. N. and Rocha, O. (2010). Aerobic and anaerobic metabolism for the zebrafish, Danio rerio, reared under normoxic and hypoxic conditions and exposed to acute hypoxia during development. Brazilian Journal of Biology 70, 425-434.

Bickler, P. E. and Buck, L. T. (2007). Hypoxia tolerance in reptiles, amphibians, and fishes: Life with variable oxygen availability. Annual Review of Physiology 69, 145-170.

Breitburg, D. L. (1992). Episodic hypoxia in Chesapeake Bay : Interacting effects of recruitment, behavior, and physical disturbance. Ecological Monographs 62, 525-546.

Bureau, D. P., Azevedo, P. A., Tapia-Salazar, M. and Cuzon, G. (2000). Pattern and cost of growth and nutrient deposition in fish and shrimp: Potential implications and applications. Avances en Nutrición Acuícola V. Memorias del V Simposium Internacional de Nutrición Acuícola, 19-22.

Cahu, C. L. and Zambonino-Infante, J. L. (1994). Early weaning of sea bass (Dicentrarchus labrax) larvae with a compound diet : Effect on digestive enzymes. Comparative Biochemistry and Physiology a-Physiology 109, 213-222. 
Cahu, C. L. and Zambonino-Infante, J. L. (1995). Maturation of the pancreatic and

362

363

364

365

366

367

368

369

370

371

372

373

374

375

376

377

378

379

380

381

382

383

384

intestinal digestive functions in sea bass (Dicentrarchus labrax): effect of weaning with different protein sources. Fish Physiology and Biochemistry 14, 431-437.

Cameron, P. and VonWesternhagen, H. (1997). Malformation rates in embryos of North Sea fishes in 1991 and 1992. Marine Pollution Bulletin 34, 129-134.

Claireaux, G. and Lagardere, J. P. (1999). Influence of temperature, oxygen and salinity on the metabolism of the European sea bass. Journal of Sea Research 42, 157-168.

Diaz, R. J. (2001). Overview of hypoxia around the world. Journal of Environmental Quality 30, 275-281.

Diaz, R. J. and Rosenberg, R. (1995). Marine benthic hypoxia: A review of its ecological effects and the behavioural responses of benthic macrofauna. Oceanography and Marine Biology - an Annual Review 33, 245-303.

Diez, J. M. and Davenport, J. (1990). Energy exchange between the yolk and embryo of dogfish (Scyliorhinus canicula L.) eggs held under Normoxic, Hypoxic and Transient Anoxic conditions. Comparative Biochemistry and Physiology B-Biochemistry \& Molecular Biology 96, 825-830.

Dufour, V., Cantou, M. and Lecomte, F. (2009). Identification of sea bass (Dicentrarchus labrax) nursery areas in the north-western Mediterranean Sea. Journal of the Marine Biological Association of the United Kingdom 89, 1367-1374.

Guderley, H. (2007). Temperature and growth rates as modulators of the metabolic capacities of fish muscle. Cold ocean physiology 66, 58.

Guderley, H., Brokordt, K., Cortes, H. M. P., Marty, Y. and Kraffe, E. (2011). Diet and performance in the scallop, Argopecten purpuratus: force production during escape responses and mitochondrial oxidative capacities. Aquatic Living Resources 24, 261-271. 
Hassell, K. L., Coutin, P. C. and Nugegoda, D. (2008). Hypoxia impairs embryo

386

387

388

389

390

391

392

393

394

395

396

397

398

399

400

401

402

403

404

405

406

407

408

409

development and survival in black bream (Acanthopagrus butcheri). Marine Pollution Bulletin 57, 302-306.

Ibarz, A., Blasco, J., Gallardo, M. A. and Fernandez-Borras, J. (2010). Energy reserves and metabolic status affect the acclimation of gilthead sea bream (Sparus aurata) to cold. Comparative Biochemistry and Physiology a-Molecular \& Integrative Physiology 155, 319-326.

Ishibashi, Y., Inoue, K., Nakatsukasa, H., Ishitani, Y., Miyashita, S. and Murata, O. (2005). Ontogeny of tolerance to hypoxia and oxygen consumption of larval and juvenile red sea bream, Pagrus major. Aquaculture 244, 331-340.

Ishibashi, Y., Kotaki, T., Yamada, Y. and Ohta, H. (2007). Ontogenic changes in tolerance to hypoxia and energy metabolism of larval and juvenile Japanese flounder Paralichthys olivaceus. Journal of Experimental Marine Biology and Ecology 352, 42-49.

Jennings, S. and Pawson, M. G. (1992). The origin and recruitment of bass, Dicentrarchus labrax, larvae to nursery areas. Journal of the Marine Biological Association of the United Kingdom 72, 199-212.

Kolkovski, S., Arieli, A. and Tandler, A. (1997). Visual and chemical cues stimulate microdiet ingestion in sea bream larvae. Aquaculture International 5, 527-536.

Lakani, F. B., Sattari, M. and Falahatkar, B. (2013). Effect of different oxygen levels on growth performance, stress response and oxygen consumption in two weight groups of great sturgeon Huso huso. Iranian Journal of Fisheries Sciences 12, 533-549.

Le Foll, C., Corporeau, C., Le Guen, V., Gouygou, J. P., Berge, J. P. and Delarue, J. (2007). Long-chain n-3 polyunsaturated fatty acids dissociate phosphorylation of Akt from phosphatidylinositol 3'-kinase activity in rats. American Journal of Physiology-Endocrinology and Metabolism 292, E1223-E1230. 
Lucassen, M., Schmidt, A., Eckerle, L. G. and Portner, H. O. (2003).

411

Mitochondrial proliferation in the permanent vs. temporary cold: enzyme activities and 412 mRNA levels in Antarctic and temperate zoarcid fish. American Journal of Physiology413 Regulatory Integrative and Comparative Physiology 285, R1410-R1420.

Massa, F., Delorme, C., Bagliniere, J. L., Prunet, P. and Grimaldi, C. (1999).

Early life development of brown trout (Salmo trutta) eggs under temporary or continuous hypoxial stress : Effects on the gills, yolk sac resorption and morphometric parameters. Bulletin Francais De La Peche Et De La Pisciculture, 421-440.

Mathers, E. M., Houlihan, D. F. and Cunningham, M. J. (1992). Nucleic acid concentrations and enzyme activities as correlates of growth rate of the saithe Pollachius virens: growth-rate estimates of open-sea fish. Marine Biology 112, 363-369.

Mazurais, D., Darias, M., Zambonino-Infante, J. L. and Cahu, C. L. (2011). Transcriptomics for understanding marine fish larval development. Canadian Journal of Zoology-Revue Canadienne De Zoologie 89, 599-611.

Ozernyuk, N. D. (2011). Adaptive specific features of energy metabolism in fish ontogenesis. Russian Journal of Developmental Biology 42, 201-205.

Padilla, P. A. and Roth, M. B. (2001). Oxygen deprivation causes suspended animation in the zebrafish embryo. Proceedings of the National Academy of Sciences of the United States of America 98, 7331-7335.

Pelster, B. (2002). Developmental plasticity in the cardiovascular system of fish, with special reference to the zebrafish. Comparative Biochemistry and Physiology a-Molecular and Integrative Physiology 133, 547-553.

Perez-Dominguez, R. and Holt, G. J. (2006). Interrenal and thyroid development in concentration during settlement. General and Comparative Endocrinology 146, 108-118. 
Pfeiler, E. (2001). Changes in hypoxia tolerance during metamorphosis of bonefish

436

437

438

439

440

441

442

443

444

445

446

447

448

449

450

451

452

453

454

455

456

457

458

459

leptocephali. Journal of Fish Biology 59, 1677-1681.

Pichavant, K., Person-Le-Ruyet, J., Le Bayon, N., Severe, A., Le Roux, A. and Boeuf, G. (2001). Comparative effects of long-term hypoxia on growth, feeding and oxygen consumption in juvenile turbot and European sea bass. Journal of Fish Biology 59, 875-883.

Pichavant, K., Person-Le-Ruyet, J., Le Bayon, N., Severe, A., Le Roux, A., Quemener, L., Maxime, V., Nonnotte, G. and Boeuf, G. (2000). Effects of hypoxia on growth and metabolism of juvenile turbot. Aquaculture 188, 103-114.

Pickett, G. D. and Pawson, M. G. (1994). Sea Bass: Biology, Exploitation and Conservation. Fish and Fisheries 12.

Pihl, L., Baden, S. P. and Diaz, R. J. (1991). Effects of periodic hypoxia on distribution of demersal fish and crustaceans. Marine Biology 108, 349-360.

Pihl, L., Baden, S. P., Diaz, R. J. and Schaffner, L. C. (1992). Hypoxia-induced structural changes in the diet of bottom-feeding fish and crustacea. Marine Biology 112, 349361.

Péres, A., Cahu, C. L., Zambonino-Infante, J. L., LeGall, M. M. and Quazuguel, P. (1996). Amylase and trypsin responses to intake of dietary carbohydrate and protein depend on the developmental stage in sea bass (Dicentrarchus labrax) larvae. Fish Physiology and Biochemistry 15, 237-242.

R Core Team. (2013). R: A language and environment for statistical computing. R Foundation for Statistical Computing, Vienna, Austria: URL : http://www.R-project.org/.

Rees, B. B., Targett, T. E., Ciotti, B. J., Tolman, C. A., Akkina, S. S. and Gallaty, A. M. (2012). Temporal dynamics in growth and white skeletal muscle composition of the mummichog Fundulus heteroclitus during chronic hypoxia and hyperoxia. Journal of Fish Biology 81, 148-164. 
Ribeiro, L., Zambonino-Infante, J. L., Cahu, C. and Dinis, M. T. (1999).

461

462

463

464

465

466

467

468

469

470

471

472

473

474

475

476

477

478

479

480

481

482

483

Development of digestive enzymes in larvae of Solea senegalensis, Kaup 1858. Aquaculture 179, 465-473.

Richards, J. G., Farrell, A. P. and Brauner, C. J. (2009). Fish Physiology, Vol. 27: Hypoxia: Academic Press, Amsterdam : Elsevier.

Roussel, J. M. (2007). Carry-over effects in brown trout (Salmo trutta): hypoxia on embryos impairs predator avoidance by alevins in experimental channels. Canadian Journal of Fisheries and Aquatic Sciences 64, 786-792.

Sanchez, R. C., Obregon, E. B. and Rauco, M. R. (2011). Vertebral Column Deformity and Hypoxia in Salmo salar. International Journal of Morphology 29, 1291-1295.

Shang, E. H. H. and Wu, R. S. S. (2004). Aquatic hypoxia is a teratogen and affects fish embryonic development. Environmental Science \& Technology 38, 4763-4767.

Thetmeyer, H., Waller, U., Black, K. D., Inselmann, S. and Rosenthal, H. (1999). Growth of European sea bass (Dicentrarchus labrax L.) under hypoxic and oscillating oxygen conditions. Aquaculture 174, 355-367.

Wei, L. Z., Zhang, X. M., Li, J. and Huang, G. Q. (2008). Compensatory growth of Chinese shrimp, Fenneropenaeus chinensis following hypoxic exposure. Aquaculture International 16, 455-470.

Wexler, J. B., Margulies, D. and Scholey, V. P. (2011). Temperature and dissolved oxygen requirements for survival of yellowfin tuna, Thunnus albacares, larvae. Journal of Experimental Marine Biology and Ecology 404, 63-72.

Wu, R., Shang, E. and Zhou, B. S. (2006). Endocrine disrupting and teratogenic effects of hypoxia on fish, and their ecological implications. In International Symposium Chongqing, China October 12-14, 2004, pp. 75. 
Zambonino-Infante, J. L. and Cahu, C. L. (2001). Ontogeny of the gastrointestinal 485 tract of marine fish larvae. Comparative Biochemistry and Physiology C-Toxicology \& 486 Pharmacology 130, 477-487.

Zambonino-Infante, J. L., Cahu, C. L. and Peres, A. (1997). Partial substitution of 488 di- and tripeptides for native proteins in sea bass diet improves Dicentrarchus labrax larval 489 development. Journal of Nutrition 127, 608-614.

490 Zambonino-Infante, J. L., Cahu, C. L., Peres, A., Quazuguel, P. and Le Gall, M. 491 M. (1996). Sea bass (Dicentrarchus labrax) larvae fed different Artemia rations: growth, 492 pancreas enzymatic response and development of digestive functions. Aquaculture 139, 129493138.

494 
495

496

497

498

499

500

501

502

503

504

505

506

507

508

509

510

511

512

513

514

515

516

517

518

519

520

521

522

523

524

525

526

\section{Figures captions:}

Fig. 1 Schema of hypoxic conditioning at $\mathbf{4 0 \%}$ air saturation. Sea bass larvae were divided into two groups : “C” represents the Control group and "HT” represents the Hypoxia Treatment group in which the level of oxygen was reduced to $40 \%$ air saturation for 8 days. Samplings were performed during hypoxia exposure (i.e. at 30, 32, 35 and 38 d.p.h.) and after the end of exposure phase (i.e. at 42 and 45 d.p.h.)

Fig. 2 Dissection performed on sea bass larvae at each sampling. Larvae were dissected into 4 parts: Head (H), Pancreatic Segment (PS), Intestinal Segment (IS) and Tail (T). H and T were systematically removed. PS were only sampled on 38-day-old sea bass larvae for pancreatic enzymes activity measurements. IS were used for all enzyme assays

\section{Fig. 3 Sea bass larvae mass for Control “C” (-) and Hypoxia Treatment “HT" (- -)} groups. Results are expressed as mean mass larvae \pm s.e.m. ( $n=4$ pools of 40 larvae). Statistical analyses revealed that larval growth rate was affected by the oxygen treatment (Two-way ANOVA: $\mathrm{p}<0.001$ ) and the age of larvae (Two-way ANOVA: p < 0.001). Significant interaction between the oxygen treatment and the age of larvae (Two-way ANOVA: $\mathrm{p}<0.01$ ) indicated that the effects of time on growth (i.e. the growth rate) depend upon the oxygen treatment. Additional statistical analyses (represent by asterisks) indicated significant differences in mass between the Control and Hypoxia Treatment groups (Studenttest: significant codes : ${ }^{*} \mathrm{p}<0.05,{ }^{* * *} \mathrm{p}<0.001$, NS $=$ No Significant differences). Refer to "Material and methods" section for more details on the statistical analyses

Fig. 4 Changes in Citrate Synthase (CS) and Cytochrome c Oxidase (COX) activities for Control "C" (white bars) and Hypoxia Treatment "HT" (grey bars) groups. A) Specific enzymatic activity of CS, B) Specific enzymatic activity of COX and C) Ratio between enzymatic activity of CS and enzymatic activity of COX. Results are given \pm s.e.m. (n = 4 pools of 40 larvae). Statistical analyses revealed that COX specific activity and CS/COX activity ratio was affected by the oxygen treatment (ANCOVA: p $<0.001$ and $\mathrm{p}<0.001$, respectively) and by the age of larvae (ANCOVA: $\mathrm{p}=0.001$ and $\mathrm{p}<0.001$, respectively). In parallel, CS specific activity was not affected by the oxygen treatment (ANCOVA: p > 0.7) but was affected by the age of larvae (ANCOVA: $p<0.001$ ). Additional statistical analyses 
527 (represent by asterisks) indicated significant differences between the Control and Hypoxia 528 Treatment groups (Student-test: significant codes : $* \mathrm{p}<0.05, * * \mathrm{p}<0.01,{ }^{* * *} \mathrm{p}<0.001$, NS $=$ 529 No Significant differences)

530 
Tables

532 Table 1: Specific activities of digestive enzymes. Results are given in milli-units per mg of protein $\left(\mathrm{mU}^{\mathrm{m}} \mathrm{mg}\right.$ protein $\left.{ }^{-1}\right) \pm \mathrm{s} . \mathrm{e} \cdot \mathrm{m}$. $(\mathrm{n}=4 * 35$ 533 larvae). Within any one column, means with the same superscript letter are not significantly different (p-value $>0.05)$. C $=\mathrm{Control}$ group; HT = 534 Hypoxia treatment group; AP = Alkaline Phosphatase; N-LAP = Aminopeptidase-N.

\begin{tabular}{|c|c|c|c|c|}
\hline & \multicolumn{2}{|c|}{ Pancreatic enzymes } & \multicolumn{2}{|c|}{ Intestinal enzymes } \\
\hline & Trypsin & Amylase & AP & N-LAP \\
\hline $\mathrm{C}$ & $42.03 \pm 4.00^{\mathrm{a}}$ & $243.89 \pm 22.56^{\mathrm{a}}$ & $1242.59 \pm 253.57^{a}$ & $204.12 \pm 43.10^{\mathrm{a}}$ \\
\hline HT & $31.41 \pm 2.21^{\mathrm{b}}$ & $608.16 \pm 112.74^{b}$ & $276.96 \pm 89.67^{b}$ & $96.84 \pm 6.81^{\mathrm{b}}$ \\
\hline
\end{tabular}


Normoxia

\section{Normoxia}

$o_{2}=96.6 \pm 1.3 \%$ air sat
$O_{2}=96.6 \pm 1.3 \%$ air sat.

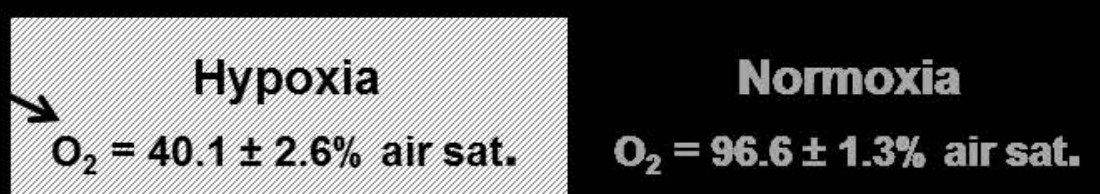




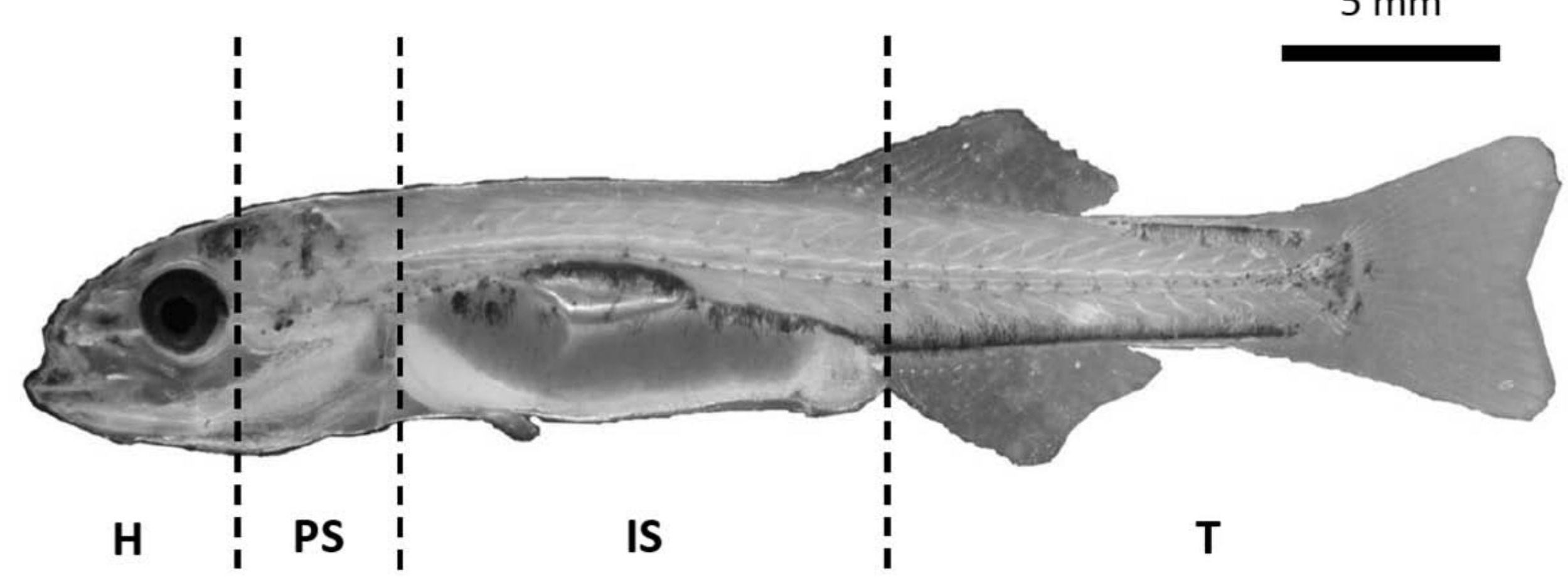




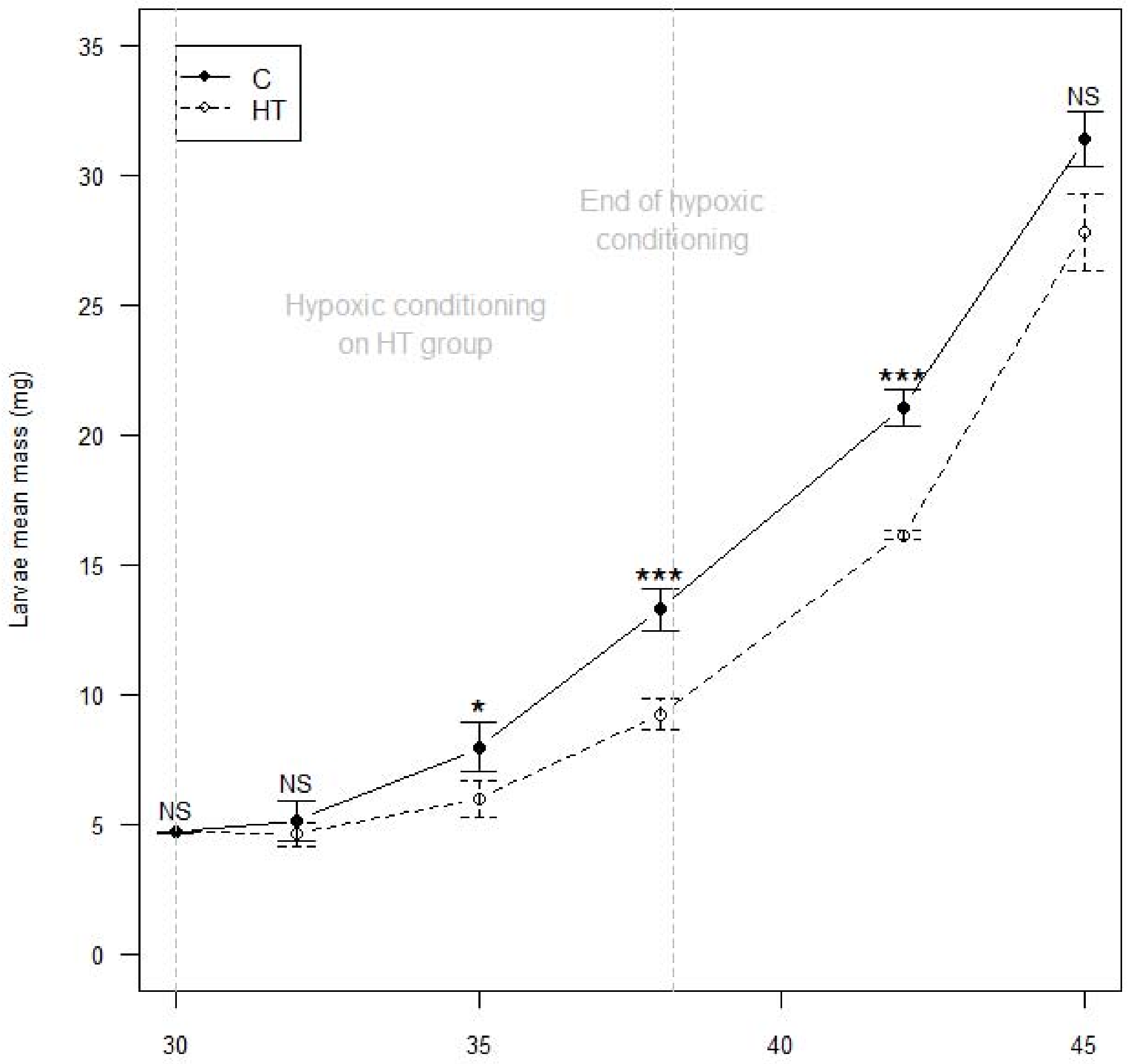

Age of larvae in days post hatching 


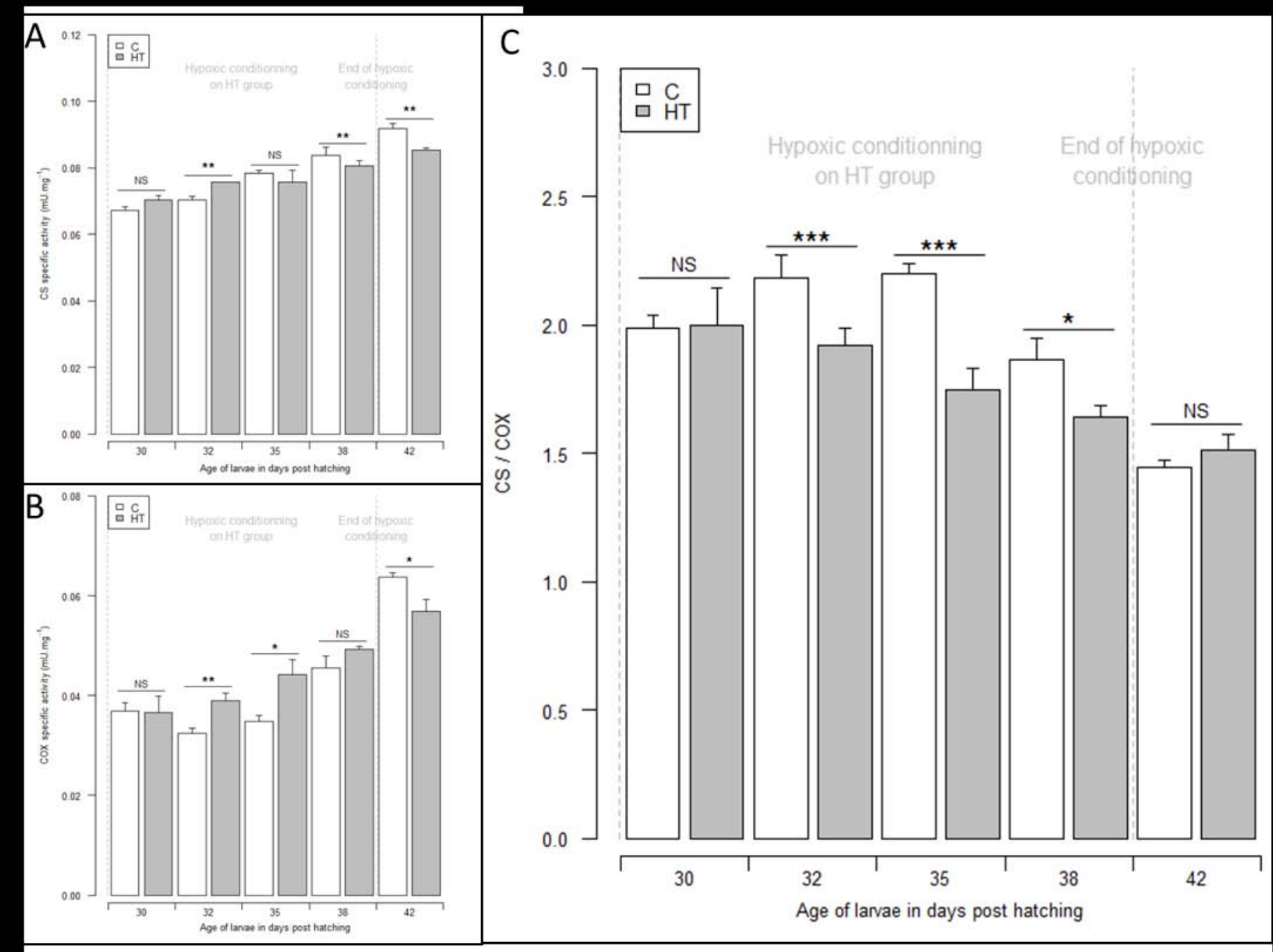

